\title{
BALANÇO HIDRICO DE UM SOLO PODZOLIZADO DE LINS E MARÍLIA CULTIVADO COM CAFEEIROS (1)
}

\author{
ANTONIO ROBERTO PEREIRA $\left({ }^{2}\right)$
}

\begin{abstract}
RESUMO
O balanço hídrico de um solo podzolizado de Lins e Marilia cultivado com cafeeiros de diferentes idades e tamanhos, ou seja, 'Mundo Novo' com livre crescimento ( 18 anos; altura $-3 \mathrm{~m}$ ), 'Mundo Novo' recepado ( 3 anos; altura $-2 \mathrm{~m}$ ) e "Catuai (4 anos; altura $-1,5 \mathrm{~m}$ ), foi realizado no período entre duas colheitas (1971/72), na Estação Experimental de Pindorama, utilizando a técnica de moderaçáo de nêutrons até $2,4 \mathrm{~m}$ de profundidade. Este tipo de solo reteve cerca de $1 \mathrm{~mm}$ de água por centímetro de profundidade quando submetido à tensāo de 15atm. A ocorrência de uma camada adensada entre 60 e $90 \mathrm{~cm}$ de profundidade ajudou a reter a umidade na parte superior do solo, dificultando a drenagem profunda. Os armazenamentos mínimo e máximo observados representaram, respectivamente, 500 e $620 \mathrm{~mm}$ para o "Catuar, 460 e $600 \mathrm{~mm}$ para o recepado, e 390 e $590 \mathrm{~mm}$ para o livre crescimento. De modo geral, pode-se dizer que: (a) o lote com livre crescimento evapotranspirou $97 \%$ do total de chuva e nāo contribuiu efetivamente com os reservatórios subterrâneos; (b) o recepado evapotranspirou $94 \%$ do total de chuva e teve uma drenagem profunda efetiva de $55 \mathrm{~mm}$; (c) o "Catuar evapotranspirou $88 \%$ do total de chuva e teve uma drenagem profunda efetiva de $152,6 \mathrm{~mm}$.
\end{abstract}

Termos de indexação: cafeeiro, solo podzolizado, evapotranspiração, drenagem profunda, armazenamento de umidade.

(1) Trabalho parcialmente financiado pelo Convênio IAC/IBC-DAC. Recebido para publicação em 27 de fevereiro de 1986. $\operatorname{nas}(\mathrm{SP})$.

(2) Seção de Climatologia Agrícola, Instituto Agronômico (IAC), Caixa Postal 28, 13001 Campi- 


\section{INTRODUÇÃO}

A camada superficial do solo é importante no ciclo hidrológico, pois é ali que ocorre interação entre a água da atmosfera e a água subterrânea, através dos processos de evaporação, transpiração, precipitação, irrigação, escorrimento superfical e drenagem profunda. Essa camada sustenta todas as atividades agricolas para as quais a água é o recurso natural mais limitante.

O solo funciona como um reservatório ativo que impõe restriçōes à utilização de seu conteúdo, limitando o fluxo de água das camadas inferiores para a superfície e desta para a atmosfera. A restrição de fluxo para a superficie reduz a evaporação tão logo o teor de umidade da superfície diminua até um valor crítico, economizando água para as plantas. Em condiçóes de alta pluviosidade, pode ser importante a quantidade de água que deixa a camada superficial do solo e atinge camadas mais profundas. Essa drenagem profunda, responsável pela recarga dos reservatórios subterrâneos, é freqüentemente desprezada em estudos de balanço hídrico: no entanto, ela pode chegar à mesma ordem de grandeza da evapotranspiração (VACHAUD et alii, 1973; PEREIRA et alii, 1974).

O uso da água do solo é um processo essencialmente energético, sendo modificado pelo tipo de planta, porcentagem de cobertura da superfície, arquitetura da planta, área foliar e sua distribuiçăo, estádio de desenvolvimento da cultura, disponibilidade de nutrientes, tipo de solo e fatores atmosféricos, que afetam a absorção e distribuição da energia pela superficie evaporante.

$O$ presente trabalho tem por objetivo descrever o balanço hidrico de um solo podzolizado Lins e Marília, variação Marília, cultivado com diferentes tipos de cafeeiros e no período entre duas colheitas.

\section{MATERIAL E MÉTODOS}

O experimento foi conduzido no ano agrícola 1971/72 na Estaçāo Experimental de Pindorama, do Instituto Agronômico, em solo classificado como Podzolizado de Lins e Marilia, variação Marília (LEPSCH \& VALADARES, 1976), situada na latitude de $21^{\circ} 10^{\prime} \mathrm{S}$., longitude $48^{\circ} 54^{\prime} \mathrm{W}$., e altitude de $560 \mathrm{~m}$.

Foi utilizado um lote de 1.024 covas do cultivar Mundo Novo, no espaçamento $3 \times 3 \mathrm{~m} ; 672$ covas haviam sido recepadas três anos antes e as demas 352, mantidas com livre crescimento (18 anos). Utilizou-se também outro lote com cerca de 300 covas do 'Catuaí, no espaçamento $3 \times 2 \mathrm{~m}$, e com quatro anos. Durante o experimento, tanto as plantas recepadas como as do. 'Catuai' cobriam aproximadamente $50 \%$ da superfície do solo, enquanto as com livre crescimento cobriam cerca de $70 \%$. As plantas com livre crescimento tinham aproximadamente $3 \mathrm{~m}$ de altura, as recepadas, cerca de $2 \mathrm{~m}$, e as do 'Catuaí, menos de $1,5 \mathrm{~m}$. 
O terreno com 'Mundo Novo' era plano, enquanto aquele com 'Catuai' tinha declive menor que $3 \%$. Nessas condições pode-se considerar o solo como um reservatório cujas trocas sejam apenas verticais, isto é, o escorrimento superficial e a drenagem lateral são despreziveis.

Considerando os caminhos que a água da chuva possa tomar e aplicando o princípio da conservação de massa num volume de solo com vegetação, tem-se a equação do balanço hídrico, isto é:

$$
P=\triangle M+D+E,
$$

onde $P$ representa a chuva; $\triangle M$, a variaçāo no armazenamento; $D$, a drenagem profunda, e $E$, a evapotranspiração. A chuva foi medida com pluviômetro instalado em área adjacente aos lotes. A variação no armazenamento foi estimada através da variação do perfil hídrico medido mensalmente com a técnica de moderação de nêutrons, sendo observados os teores de umidade a cada $30 \mathrm{~cm}$ até a profundidade de $2,4 \mathrm{~m}$. Neste tipo de solo, a maior parte do sistema radicular do cafeeiro se encontra nos primeiros $80 \mathrm{~cm}$, havendo, porém, quantidade significativa de radicelas até $130 \mathrm{~cm}$, com algumas chegando até $190 \mathrm{~cm}$ (FRANCO \& INFORZATO, 1946). Para acesso da sonda de nêutrons foram instalados, em cada lote, três tubos de alumínio sem costura entre as plantas na linha de plantio.

A drenagem profunda foi estimada segundo metodologia descrita por ROSE (1966) e modificada por BLACK et alii (1969), que supõe que na profundidade $\mathrm{Z}$ a drenagem é proporcional ao armazenamento na camada acima de $\mathrm{Z}$, e que nesta profundidade o gradiente de potencial total é unitário. As características hídricas da camada mais profunda do perfil foram determinadas em laboratório e a condutividade hidráulica, pela técnica descrita por LIBARDI \& REICHARDT (1973). A densidade aparente do perfil foi determinada através de amostras coletadas com anel volumétrico. A evapotranspiração foi determinada como resíduo da equação (1).

\section{RESULTADOS E DISCUSSÃO}

Os resultados obtidos evidenciam o efeito do tamanho das plantas sobre o balanço hídrico do solo. De modo geral, há associação entre o tamanho da planta e sua área foliar, isto é, plantas maiores apresentam maior área foliar, portanto, maior superfície evaporante.

A figura 1 mostra a variação sazonal da água disponivel até a profundidade de 2,4m no período entre duas colheitas (1971/72). Esse tipo de solo reteve em seu perfil $(0-240 \mathrm{~cm}$ ) cerca de $250 \mathrm{~mm}$ de água quando submetido à tensão de $15 \mathrm{~atm}$, correspondente a aproximadamente $1 \mathrm{~mm}$ de água por centímetro de solo. Considerou-se como água disponivel somente a umidade contida acima deste limite. O ritmo da disponibilidade hídrica seguiu o das chuvas, não havendo deficiência no período estudado. $O$ ano agrícola $1971 / 72$ pode ser considerado nor- 
mal, porém com inverno mais chuvoso. $O$ tamanho das plantas condicionou um escalonamento na disponibilidade hídrica das três culturas, ou seja, a disponibilidade foi maior no lote com 'Catuaí, seguido pelo lote recepado, e menor no lote com livre crescimento. $O$ paralelismo das curvas de disponibilidade hidrica foi eliminado quando da ocorrência de chuvas mais intensas no verão, após dezembro. Isso evidencia que, no verāo, o solo esteve sempre próximo de sua capacidade máxima de retenção de umidade, havendo sempre excedente hidrico. $O$ lote com 'Catuaî atingiu armazenamento máximo cerca de um mês antes dos outros.

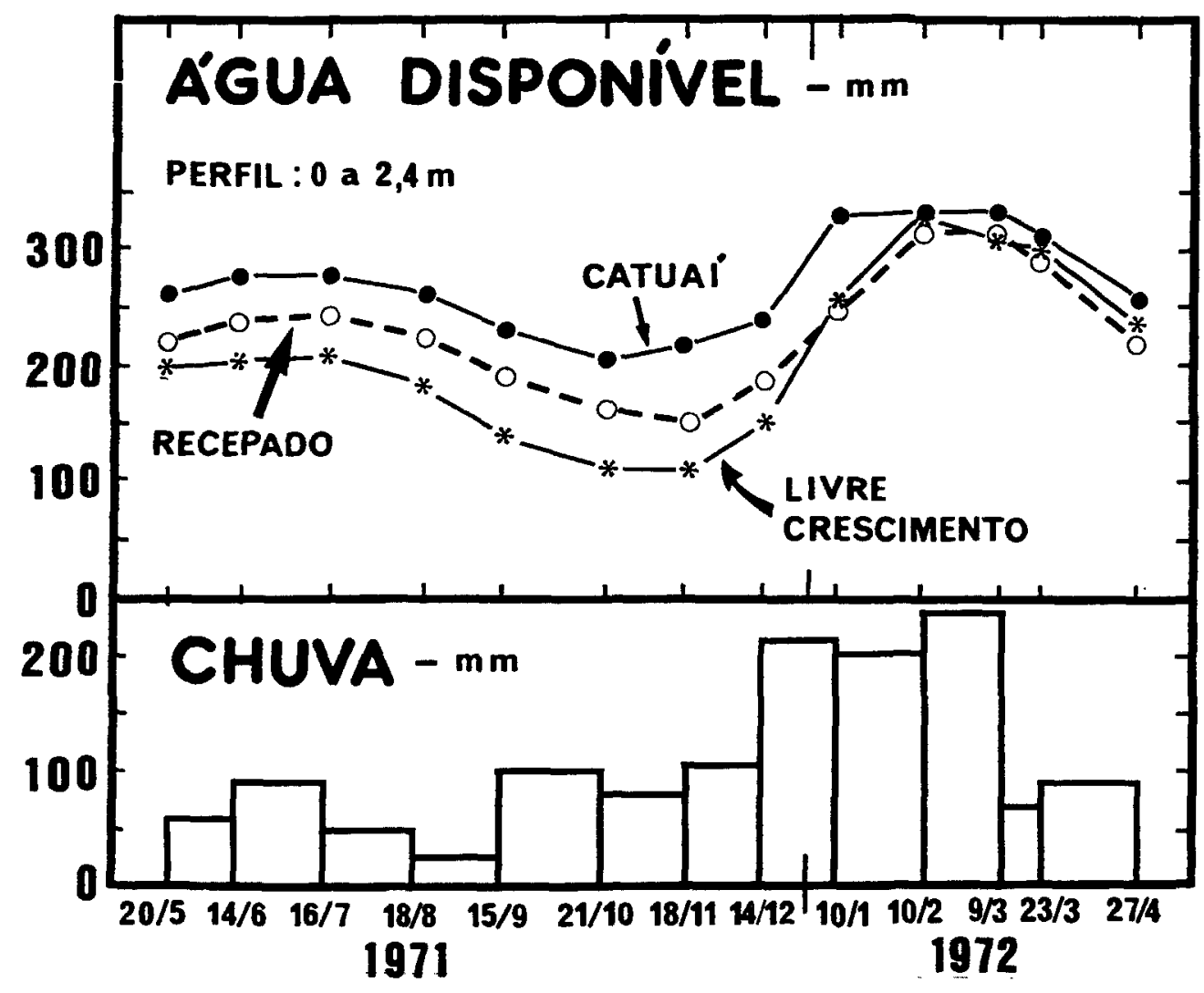

FIGURA 1. Variação sazonal das chuvas e da disponibilidade hídrica em solo podzolizado de Lins e Marília cultivado com cafeeiros. Pindorama, SP, 1971/72.

A figura 2 mostra a distribuiçáo da umidade no perfil de solo em duas situaçōes distintas, ou seja, os perfis minimo e máximo observados. Em todos os lotes, o perfil minimo ocorreu em meados de outubro, e o máximo, em fevereiro. 


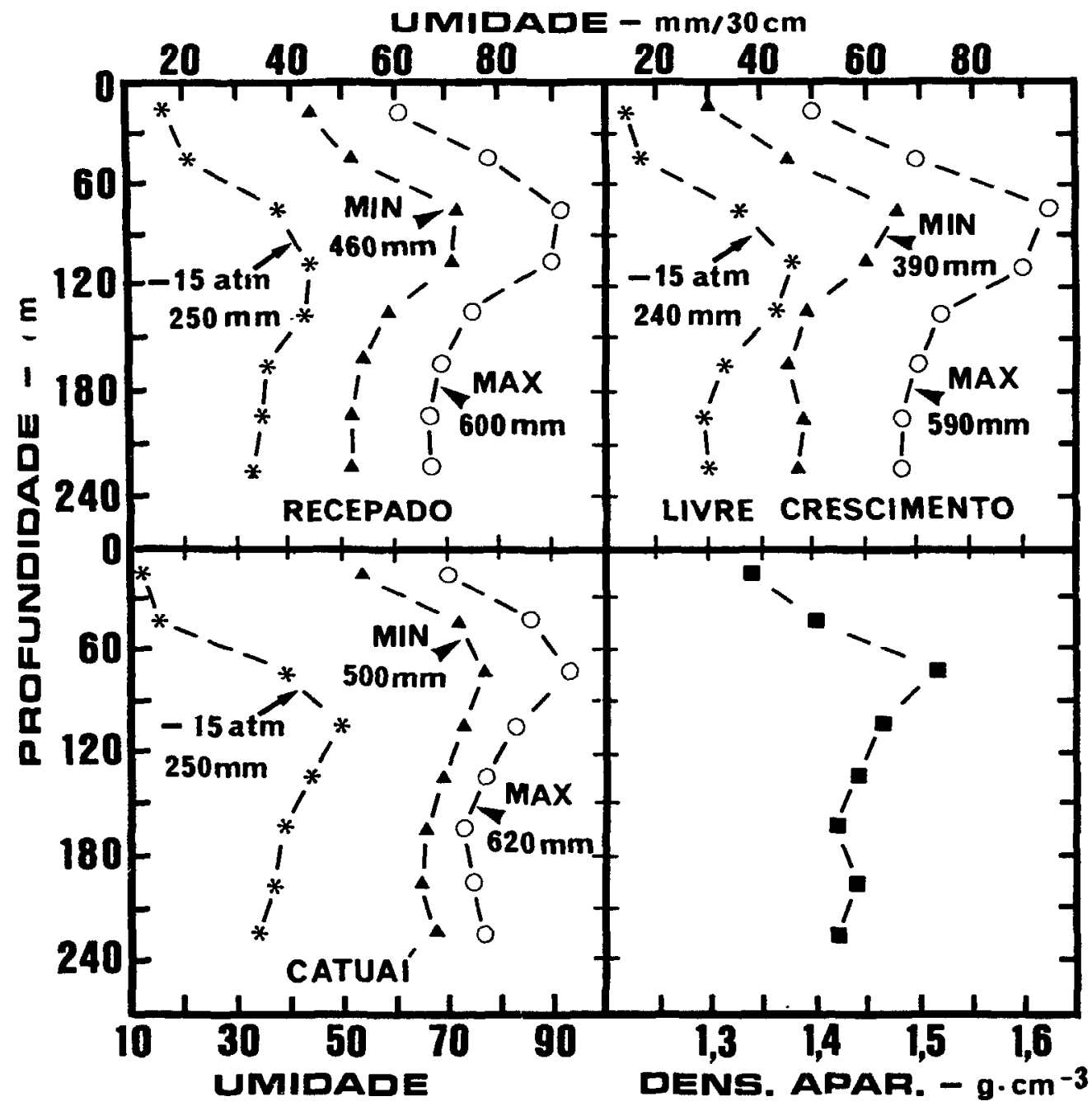

FIGURA 2. Perfis de umidade e de densidade aparente de um solo podzolizado de Lins e Marilia cultivado com cafeeiros. Pindorama, SP, 1971/72.

A quantidade de água retida quando da ocorrência do perfil mínimo foi de $500 \mathrm{~mm}$ para o 'Catuaî, $460 \mathrm{~mm}$ para o lote recepado, e $390 \mathrm{~mm}$ para o lote com livre crescimento. Em nenhuma camada o perfil mínimo se aproximou da curva de água retida a $15 \mathrm{~atm}, 250 \mathrm{~mm}$ para os lotes com 'Catuaí' e recepado, e $240 \mathrm{~mm}$ para o lote com livre crescimento. O perfil mínimo indica que o ano agricola 1971/72 foi favorável, em termos hídricos, ao desenvolvimento do cafeeiro naquela região. 
Verificou-se, ao redor de $60-90 \mathrm{~cm}$ de profundidade, a ocorrência de uma camada adensada que ajudou a reter a umidade na parte superior do solo, dificultando a drenagem profunda do excedente hídrico. Na época de chuvas intensas, o perfil máximo representou armazenamento de $620 \mathrm{~mm}$ para o 'Catuai', $600 \mathrm{~mm}$ para o lote recepado e $590 \mathrm{~mm}$ para aquele com livre crescimento.

Considerando os teores máximo e minimo de umidade em cada profundidade no decorrer do ano, o máximo de umidade extraida por camada de $30 \mathrm{~cm}$ de solo variou entre $15 \mathrm{~mm}$, para o 'Catuai', e $38 \mathrm{~mm}$, para o livre crescimento (Quadro 1). O lote com livre crescimento apresentou maior extração de umidade em todas as camadas, enquanto o recepado teve maior extração que o 'Catuai" somente até $120 \mathrm{~cm}$ de profundidade. Isso evidencia diferenças no tamanho do sistema radicular das plantas, que deve ser proporcional ao tamanho da parte aérea. As extrações foram maiores nas camadas superficiais, evidenciando a maior concentração e atividade das raízes em tal profundidade.

A umidade extraida do perfil pode ter dois destinos: evapotranspiração e drenagem profunda. Ainda não é possivel a medição direta in situ da drenagem profunda. Quanto à evapotranspiração, sua medição em condições naturais é extremamente difícil e onerosa, e alguns métodos introduzem artificialidades que distorcem os resultados. Portanto, se se quiser ter uma idéia da ordem de grandeza desses fluxos, deve-se lançar mão de estimativas. Pela natureza das medigōes envolvidas, optou-se pela estimativa da drenagem profunda pelo método de BLACK et alii (1969).

QUADRO 1. Máximo de umidade extrá́da por camada de um solo podzolizado de Lins e Marilia, variação Marilia, cultivado com cafeeiros, durante o ano agrícola 1971/72. Pindorama, SP

\begin{tabular}{lccc}
\hline Profundidade & $\begin{array}{c}\text { 'Mundo Novo' } \\
\text { Livre crescimento }\end{array}$ & $\begin{array}{c}\text { 'Mundo Novo' } \\
\text { Recepado }\end{array}$ & 'Catua' \\
\hline $\mathrm{cm}$ & & $\mathrm{mm}$ & \\
\cline { 2 - 4 } $0-30$ & $38 \pm 4$ & $33 \pm 6$ & $33 \pm 4$ \\
$30-60$ & $37 \pm 6$ & $34 \pm 6$ & $17 \pm 3$ \\
$60-90$ & $30 \pm 4$ & $23 \pm 2$ & $21 \pm 2$ \\
$90-120$ & $31 \pm 3$ & $24 \pm 4$ & $20 \pm 1$ \\
$120-150$ & $26 \pm 4$ & $22 \pm 1$ & $21 \pm 2$ \\
$150-180$ & $25 \pm 5$ & $18 \pm 2$ & $19 \pm 2$ \\
$180-210$ & $21 \pm 5$ & $16 \pm 1$ & $17 \pm 2$ \\
$210-240$ & $22 \pm 5$ & $19 \pm 1$ & $15 \pm 1$ \\
$0-240$ & $230 \pm 5$ & $189 \pm 3$ & $163 \pm 2$ \\
\hline
\end{tabular}







O quadro 2 apresenta o balanço hídrico completo dos três lotes. Os pluviômetros indicaram uma diferença menor que $2 \%$ entre o total de chuvas ocorridas nos lotes, insuficiente para invalidar as comparações. Considerando que parte dos resultados é fruto de estimativas e, portanto, deve ser tomada com reservas, verifica-se que o total evapotranspirado foi de $1.355,2 \mathrm{~mm}$ para o lote com livre crescimento, $1.311,3 \mathrm{~mm}$ para o recepado, e $1.230 \mathrm{~mm}$ para o 'Catuaî. Houve, portanto, uma diferença menor que $10 \%$ entre os valores extremos de evapotranspiração.

No lote com livre crescimento, a evapotranspiração total representou cerca de $97 \%$ do total de chuvas. Nos outros, tal índice chegou a 94 no recepado e $88 \%$ no 'Catual. Nos três lotes, cerca de 50-60\% da evapotranspiração ocorreu nos meses onde as chuvas foram mais intensas, e o crescimento das plantas também. Em alguns periodos após dezembro, a evapotranspiração foi elevada. Valores de evapotranspiração média acima de $5-6 \mathrm{~mm} / \mathrm{d}$ por periodo tão longo indicam que as estimativas de drenagem profunda foram deficientes.

Ressalvando a deficiência de estimativa da drenagem profunda, vale notar que, durante o período total, o lote com 'Catuaî' contribuiu com 152,6mm para as camadas abaixo de $2,4 \mathrm{~m}$ de profundidade; o recepado, com $55 \mathrm{~mm}$, e o lote com livre crescimento, não só não teve drenagem profunda efetiva como ainda utilizou cerca de $17 \mathrm{~mm}$ das camadas inferiores.

No lote com 'Catuar, onde a drenagem profunda foi maior, em alguns periodos ela representou mais de $30 \%$ da evapotranspiração do mesmo período. No global, esse índice chegou a $12 \%$.

\section{SUMMARY}

\section{WATER BALANCE OF A PODZOLIC SOIL GROWN WITH COFFEE TREES}

The water balance of an euthrophic red yellow podzolic soil grown with coffee trees of different ages and sizes, that is, 'Mundo Novo' with normal gro w th (18 years - 3m tall), 'Mundo Novo' cut back ( 3 years $-2 \mathrm{~m}$ tall), and 'Catuai' ( 4 years $-1.5 \mathrm{~m}$ tall) were performed during the period between two harvests (1971/72), in Pindorama, State of São Paulo, Brazil, through the neutron technique down to the $2.4 \mathrm{~m}$ depth. Such soil held about $1 \mathrm{~mm}$ of water per centimeter of soil depth when under the tension of 15atm. There was a dense layer between 60 and $90 \mathrm{~cm}$ which helped to keep the moisture in the upper part of the soil profile and restricted the deep drainage. The minimum and maximum storage observed were, respectively, 500 and $620 \mathrm{~mm}$ for 'Catuar', 460 and $600 \mathrm{~mm}$ for the cut back field, and 390 and $590 \mathrm{~mm}$ for the field with normal growth. In general we can say that: $(a)$ the normal growth field used about $97 \%$ of the total rainfall as evapotranspiration and did not have an effective deep drainage; (b) the evapotranspiration of the cut back 
field was about $94 \%$ of the total rainfall with an effective deep drainage of $55 \mathrm{~mm}$; $(c)$ the "Catuar field evapotranspired about $88 \%$ of the total rainfall and contributed effectively with $152.6 \mathrm{~mm}$ to the deep drainage.

Index terms: coffee trees, podzolic soil, evapotranspiration, deep drainage, moisture storage.

\section{REFERÊNCIAS BIBLIOGRÁFICAS}

BLACK, T.A.; GARDNER, W.R. \& THURTELL, G.W. The prediction of evaporation, drainage and soil water storage for a bare soil. Proceedings of Soil Science Society of America, 33:655-660, 1969.

FRANCO, C.M. \& INFORZATO, R. O sistema radicular do cafeeiro nos principais tipos de solos do Estado de Sấo Paulo. Bragantia, Campinas, 6:443-478, 1946.

LEPSCH, I.F. \& VALADARES, J.M.A.S. Levantamento pedológico detalhado da Estação Experimental de Pindorama - SP. Bragantia, Campinas, 35:13-40, 1976.

LIBARDI, P.L. \& REICHARDT, K. Características hídricas de cinco solos do Estado de São Paulo. II. Curvas de retenção e condutividade hidráulica. In: CONGRESSO BRASILEIRO DE CIÊNCIA DO SOLO, 14., Santa Maria, 1973. Anais. p.140-148.

PEREIRA, A.R.; FERRAZ, E.S.B.; REICHARDT, K. \& LIBARDI, P.L. Estimativa da evapotranspiraçāo e da drenagem profunda em cafezais cultivados em solos podzolizados Lins e Marília. Piracicaba, CENA-ESALQ, 1974. 14p. (Boletim científico, 14)

ROSE, C.W. Some experimental aspects of crop water use studies in the field. In: Agricultural Physics. Oxford, Pergamon Press, 1966. Chapter 7, p.178-199.

VACHAUD, G.; TEHEL, J.; ROYER, J.M. \& BOLCATO, R. Controle automatique in-situ des transfers d'eau dans la zone non saturée: application à la determination du bilan hydrique. Vienna, International Atomic Energy Agency, 1973. 26p. 